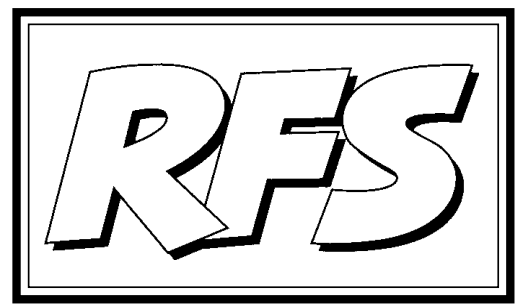

Revista de Fomento Social, 54 (1999), 309-341

\title{
Neoliberalismo y Estado social
}

Este artículo recoge el texto de la ponencia presentada el 20 de Febrero de 1998, en el marco del Seminario de Investigación «Francisco Suárez», en ETEA-Córdoba. En el trabajo se resumen y justiprecian algunos de los más importantes ataques teóricos contra el Estado social, formulados por autores de inspiración neoliberal. En la segunda parte, el autor propone algunos contra-argumentos, aduce las razones por las que, en su opinión, el Estado social representa una conquista civilizatoria irrenunciable, y apunta posibles líneas de evolución futura. Las notas finales proporcionan pistas bibliográficas, al tiempo que desarrollan y redondean algunos argumentos sólo escuetamente esbozados en el texto de la ponencia.

(*)Profesor Titular del Departamento de Filosofía del Derecho de la Universidad Hispalense (Sevilla). 


\section{Introducción}

Querría antes que nada expresar mi sincera gratitud al profesor Theotonio y a los demás organizadores por haberme brindado, ya por segunda vez, la oportunidad de dirigirme a Vds. en el marco de este seminario. He rotulado mi ponencia con el título «Neoliberalismo y Estado social» porque en ella pasaré revista a una serie de argumentos contrarios al Estado redistribuidor-asistencial, argumentos que, en su mayoría, fueron inicialmente expuestos por autores encuadrables en ese sector intelectual (si bien, algunas de esas tesis anti-welfare, sin duda porque en ellas había al menos una parte de verdad, han ido irradiando a otros campos ideológicos, y en la actualidad han permeado prácticamente a la totalidad de la opinión pública). La ofensiva teórica neoliberal contra el Estado del Bienestar ha terminado teniendo éxito, y hoy ese modelo estatal parece encontrarse en todas partes «bajo sospecha». Se oye constantemente hablar de la insostenibilidad del Estado social; muchos lo consideran un modelo anacrónico, incapaz de adaptarse a las nuevas circunstancias, incompatible con el crecimiento económico, anquilosado por la hiperburocratización, culpable de hemorragias presupuestarias irrestañables, propiciador de abusos, generador de pereza e irresponsabilidad en los cuidadanos... En mi ponencia intentaré pergeñar una síntesis de los más importantes de esos argumentos, para a continuación exponer mi propia posición.

\section{2. ¿Es económicamente insostenible el Estado social?}

Uno de los argumentos más utilizados por los críticos del Estado social es el de su supuesta inviabilidad presupuestaria: «no salen las cuentas», el Estado social resulta demasiado caro; el Estado asistencial hallegado a convertirse en un «pozo sinfondo» devorador de recursos, una hemorragia presupuestaria permanente; en definitiva: un lujo que ya no nos podemos permitir.

Los portavoces de este tipo de argumentación aducen constataciones aparentemente irrefutables. El porcentaje de gasto público en relación alP.I.B. ha crecido constantemente en los países occidentales desde el final de la Segunda Guerra Mundial (elEstado absorbe una parte cada vez mayor de la riqueza nacional). Uno de los factores (noelúnico) que explican ese incremento constante del gasto público es la necesidad de sufragar las prestaciones sociales características del Estado del Bienestar: sanidad y educación públicas, subsidios de desempleo, pensiones de 
jubilación, etc. Esto significa que el gasto social crece más rápido que la economía (más rápido que la producción); de ahí que las prestaciones sociales absorban un porcentaje cada vez mayor del producto nacional (1).

Se intuye fácilmente que ese desfase entre el ritmo de incremento del gasto público y el ritmo de crecimiento de la economía de un país no puede mantenerse indefinidamente, pues entonces llegaría un momento en que el Estado absorbiese el 100\% de la riqueza nacional: habríamos desembocado en la colectivizaciónsocialización total de la economía. Pero ese supuesto de estatalización total nunca llegará a verificarse, porque mucho antes de llegar a él sobrevendrá la bancarrota; según algunos economistas, existiría un «umbral crítico» en el porcentaje de recursos de un país que pueden ser absorbidos por el Estado (un límite objetivo de la presión fiscal que puede tolerar un país); si se rebasa ese listón, primero se inhibe el crecimiento, y después se desemboca sencillamente en el colapso socio-económico. Y bien, las economías europeo-occidentales supuestamente o habrían rebasado ya, o estarían a punto de rebasar ese «umbral de tolerancia» (2).

E. GIL CALVO se ha referido ingeniosamente a ese problema de financiación del Estado social como una nueva versión de la «maldición malthusiana». Es sabido que el economista T.R. MALTHUS esbozó a comienzos del siglo XIX un escenario catastrofista, en el que el incremento desbocado de la población (que puede llegar a crecer en progresión geométrica) sobrepasa en mucho al incremento de la producción (que sólo puede crecer en progresión aritmética), una evolución que conduciría indefectiblemente a la hecatombe si no fuera porque hasta el momento vienen actuando frenos demográficos (como las malas cosechas, las

(1) Una formulación incisiva de la tesis según la cual «elEstado asistencial tiende a crecer más rápido que los medios para financiarlo» puede encontrarse en O'CONNOR, J., The Fiscal Crisis of the State, St.Martin Press, Nueva York, 1973; O'CONNOR enfoca la crisis del Estado asistencial desde una óptica próxima al marxismo, dedicando especial atención a la supuesta contradicción entre las «funciones de acumulación» y las «funciones de legitimación» propias de aquél.

(2) Sobre los problemas de financiación del Estado social, vid. Rosanvallon, P., La crise de l'Etat-providence, Seuil, París, 1992, p. 13; HANSEn, V., «Sozialstaat vor dem Umbau.Reformansätze aus Sicht der Arbeitgeber», en SchÖNIG, W. - L'HOEST, R. (eds.), Sozialstaat wohin? Umbau, Abbau oder Ausbau der sozialen Sicherung, Wissenschaftliche Buchgesellschaft, Darmstadt, 1996, p. 121; AlBERT, M., Capitalismo contra capitalismo, trad. de J.F. Delos, Paidós, Barcelona, 1992, p. 152 y ss. 
epidemias, las guerras...) que contienen, mal que bien, el crecimiento de la población y aplazan provisionalmente la catástrofe. Pues bien, la versión «neomalthusiana» de esa evolución fatal propone, no ya al crecimiento incontrolado de la población, sino al crecimiento de los gastos sociales (o, más genéricamente, del gasto público) como la nueva bomba de relojería que amenaza con hacerestallar a las sociedades contemporáneas (3).

Por otra parte, si la versión originaria de la «maldición malthusiana» veía la amenaza principal en un incremento demográfico demasiado rápido, la nueva versión, en cambio, descubre el peligro precisamente en lo contrario: el excesivo descenso del índice de natalidad aboca a las sociedades desarrolladas al envejecimiento paulatino. Se produciría así una inversión progresiva de la pirámide demográfica, que tornaría aún más problemática la financiabilidad del Estado social: al disminuir el porcentaje de personas en edad de trabajar, ocurrirá que una franja cada vez más restringida de contribuyentes activos tendrá que hacerse cargo de las necesidades de una masa cada vez mayor de jubilados improductivos. Pero eso parece insostenible a medio plazo (4) (de hecho, las compañías privadas de seguros utilizan ya como argumento publicitario la idea de la futura quiebra ineluctable de la Seguridad Social...).

Un argumento tradicional de los críticos del Estado social es que ese dinamismo expansivo, esa propensión aparentemente imparable al incremento del gasto, es consustancial al Estado asistencial. El Estado social, según ellos, poseería una tendenciaintrínsecaalahipertrofia, a la elefantiasis. YaW.V.HUMBOLDT, afinales del siglo XVIII (en una obra titulada «Los límites de la acción del Estado»), llamó la atención sobre esa pulsión hipertrófica característica delEstado-providencia: «cada diez años tiene lugar en la mayoría de los Estados una ampliación del número de funcionarios, una extensión de la burocracia y, por tanto, una restricción cada vez

(3) Gil Calvo, E., «La trampa postmalthusiana», El País, 20-04-1994, p. 15.

(4) Según las proyecciones estadísticas del Verband Deutscher Rentenversicherungsträger, en caso de persistir las tendencias demográficas actuales, para el año 2030 el mantenimiento de las pensiones dejubilaciónen Alemaniaexigiríaque las cotizaciones sociales seincrementasenenun 50\% respecto a los valores actuales, y que el porcentaje de gasto público respecto al P.I.B. pasase desde el 39'3\% actual hasta el 49'8\%. La viabilidad económica de semejante incremento es, según ese organismo, sumamente cuestionable. Vid. HANSEN, V., «Sozialstaat vordem Umbau», cit., p. 125; BZCKER, G., «Sozialpolitik zwischen Abbau und Umbau. Reformansätze aus SichtderGewerkschaften», en SCHÖNIG, W. - L'HOEST, R. (eds.), Sozialstaat wohin?, cit., p. 147. 
mayor de la libertad de los ciudadanos» (5). Como vemos, HUMBOLDT asocia automáticamente el desarrollo de laburocracia estatal con la restricción de la libertad individual (esaecuación simplista según la cual «másEstado» significaindefectiblemente «menos libertad» es muy característica de la mentalidad liberal; muchos neoliberales actuales siguen creyendoen ello a pies juntillas). También el economista A. WAGNER formuló a finales del siglo XIX una «ley de la extensión creciente de la actividad estatal en los pueblos civilizados que progresan». WAGNER, adiferencia deHUMBOLDT, propone unainterpretación optimista deese crecimientoindefinido de la intervención estatal en la sociedad. En las sociedades civilizadas, según WAGNER,elEstadoestállamado a corregir las injusticias distributivas del mercado y a garantizar la cobertura de las necesidades elementales de todos los ciudadanos, y eso implica una intervención cada vez mayor, y también un gasto público cada vez mayor: «cuanto más se civiliza la sociedad, más dispendioso es el Estado», llega a afirmar literalmente WAGNER(6).

Huelga decir que muchos autores actuales no comparten esa virginal confianza de WAGNER en las virtudes civilizadoras del gasto público. Así, algunos teóricos estiman que el crecimiento incesante de la actividad estatal no se debe tanto a factores exógenos (por ejemplo, que haya más necesidades que atender o más problemas que resolver) como a factores endógenos (factores inherentes a la propia naturaleza y principios de funcionamiento de la Administración pública). F.A. HAYEK, por ejemplo, llamó la atención sobre el papel de los llamados «expertos» (técnicos de todo tipo que, o pertenecen a la propia Administración, o deambulan en sus aledaños); según HAYEK, los «técnicos»o «expertos» se pronunciarán sistemáticamente en favor de la ampliación de los organismos públicos a los que asesoran (y de cuyo presupuesto cobran), con independencia

(5) Humboldt, W.V., Los límites de la acción del Estado, trad. cast. de J.Abellán, Tecnos, Madrid, 1988, p. 39. Añade HumBoldT: «Todo el que haya tenido ocasión de intervenir en la alta administración del Estado sabe por experiencia cuán pocas medidas responden en rigor a una necesidad directa, absoluta, y cuántas, por el contrario, a una necesidad indirecta, relativa, impuesta por otras medidas precedentes. Esto hace necesaria una cantidad incomparablemente mayor de medios, los cuales quedan sustraídos a la consecución del verdadero fin. No es solamente que un Estado así requiere mayores ingresos, sino que reclama también instituciones más artificiales [...]», op. cit., p. 38 .

(6) Wagner, A., Fundamentos de Economía Política (citado por Rosanvallon, P. , op. cit., p. 152). 
de si ello es o no objetivamente necesario (7). También W. NISKANEN sostiene que todoadministrador público aspira indefectiblemente a ampliar hastael máximo el presupuesto que maneja y el tamaño del organismo, institución o agencia que dirige. En esto, la burocracia estatal no diferiría esencialmente de las empresas privadas, las cuales también tienden naturalmente a crecer. La diferencia estribaría en que el crecimiento de las empresas privadas está constreñido por los mecanismos selectivo-competitivos característicos del mercado (en el mercado privado no crece quien quiere, sino quien puede: quien obtiene beneficios, quien tiene éxito).La Administración pública, en cambio, no está sometida a esas restricciones competitivas (o lo está en mucho menor medida), y, por tanto puede crecer indefinidamente. Y, según estos autores (NISKANEN, KRISTOL, WILDAWS$\mathrm{KY}$, etc.) (8), ese «monstruo» burocrático hipertrofiado, en expansión permanente, hallegado a convertirse en el problema principal de las sociedades desarrolladas.

(7) Vid. Hayek, F.A., The Constitution of Liberty, The University of Chicago Press, Chicago, 1960 (especialmente la tercera sección, «Freedom in the Welfare State»).

(8) Vid. Niskanen, W., Bureaucracy and Representative Government, Aldine, Chicago, 1971; Kristol, I., Two Cheers for Capitalism, Basic Books, Nueva York, 1978; Meltzer, A.H, RichaRD, S.F., «Why Government Grows (and Grows) in a Democracy», The Public Interest, n. 51, verano, 1978; P.L. BERGER atribuye una responsabilidad importante en la expansión incontrolada del Estado asistencial a la presión de la «clase del conocimiento» (knowledge class), formada por «personas cuyas ocupaciones tratan de la producción y distribución de conocimientos simbólicos [...], personas empleadas en el sistema educativo, los medios de comunicación, las grandes redes de asesoramiento y orientación, y las agencias burocráticas que planifican las necesidades no materiales de la sociedad (desde la concordia racial hasta el recreo geriátrico)»(BERGER, P.L., La revolución capitalista,Península, Barcelona, 1991, pp. 84-85). Esta clase de pseudo-intelectuales y trabajadores sociales (docentes, psicólogos, sociólogos, etc.) se caracteriza, según BERGER, por sus actitudes «idealistas-progresistas» y por defender a ultranza «la expansión delEstado benefactor» (op. cit., p. 88). Lodefienden, fundamentalmente, porque comen deél: «una gran parte de estaclase del conocimientodepende, para ganarse la vida, delas nóminas o subsidios gubernamentales» (p. 88). Perola «clasedel conocimiento»oculta su interés de clase (favorable a la expansión delEstado asistencial) tras la excusa del interés altruista por los desfavorecidos: no reconocen estar defendiendo sus propios salarios, sino que invocan las supuestas necesidades de los más pobres. «Estoha supuesto políticamente [...] unacuriosasimbiosis entre este grupo, por lo general rico y bien educado, y [...]varios grupos de la «clase baja». Por supuesto, el interés común se centra en [la potenciación del] papel distributivo y redistributivo del Estado» (op. cit.,p. 89). Sobre lainfluencia de esta «clase del conocimiento», vid. también KRISTOL, I., Reflections of a Neoconservative, Basic Books, Nueva York, 1983, pp. 211-212. 


\section{Estado social y globalización}

Un segundo factor que parece amenazar la supervivencia del Estado social es la «globalización» o mundialización económica. Debe tenerse presente que el Estado social representa, en términos globales, un intento de domesticación o civilización de la competición económica: el poder estatal reglamenta esa competición, le impone unas condiciones y unos límites, confisca una parte de los beneficios de los «ganadores» para garantizar ciertos servicios mínimos a los «perdedores»...En cambio, las tendencias actuales de la economía mundial parece que apuntan en la dirección de la desregulación, la liberalización, el abandono de cualesquiera controles o reglas del juego. Los Estados se descubren impotentes para embridar o encauzar un mercado internacional de capitales y servicios que arrolla cualesquiera reglamentaciones o barreras nacionales y se mueve exclusivamente en virtud de su propia lógica y sus propios impulsos (es definitivamente autónomo). Es preciso tomar conciencia de la increíble volatilidad (movilidad) del mercado financierointernacional actual. Por ejemplo, en un día normal del mercado internacional decambios, el valor de todas las transaccionesque serealizan enel mundo puede llegar a un billón de dólares. Esoequivale aproximadamente al P.I.B. anual de un país como Francia. (Las reservas de todos los bancos centrales del mundo suman sólo unos 800.000 millones de dólares, una cifra inferior) (9). Esas transacciones, además, se producen a una velocidad literalmente supersónica: las innovaciones tecnológicas permiten ya operaciones «on line» (en tiempo real) por medio de ordenadores interconectados porhilotelefónico a todos los mercados, de manera que sólo transcurren centésimas de segundoentre la decisión y el acto de comprar o vender (por ejemplo, unos bonos en moneda extranjera o unos títulos de deuda) (10).

(9) Datos ofrecidos por De SebAStián, L., «Encadenar a tiempo al gigante especulativo», Cuatro Semanas, Febrero, 1993, p. 18.

(10) L. De Sebastián subraya también la propensión del capital internacional a las reacciones hiperemotivas y desproporcionadas. Así, DE SEBASTIÁN califica de «neurótico» el comportamiento de los mercados con ocasión de la crisis mexicana de las primeras semanas de 1995, cuando una devaluación torpemente explicada por el gobierno hizo cundir el pánico en los inversores extranjeros, que comenzaron a abandonar fulminantemente el país (las ondas desestabilizadoras generadas por esta crisis se extendieron a la mayoría de las economías latinoamericanas; los analistas bautizaron el fenómeno como «efecto tequila»). Este tipo de desbandadas irracionales (desproporcionadas respecto a la gravedad real de los síntomas que las 
Esto significa que existe ya un único mercado mundial del dinero, que desprecia las fronteras y, en cierto modo, obliga a los Estados a someterse. «El mundo escribe el Premio Nobel M. ALLAIS- se ha convertido en un inmenso casino, donde las mesas de juego están repartidas en todas las longitudes y todas las latitudes» (11). Ha comenzado -escribe R. PETRELLA- la era de la economía «post-nacional», y eso implica la progresiva superación o relativización de los principios, reglas y modos de organización característicos del sistema «nacional»: Estado nacional, economía nacional, moneda nacional, Derecho nacional...(12).

ocasionan) del capital internacional pueden hundir o perjudicar seriamente las perspectivas económicas de un país. Más aún, dada la absoluta interdependencia de los mercados financieros, esas reacciones «histéricas» pueden producir una sacudida en cadena que vaya creciendo en ondas concéntricas y termine dejándose sentir en todo el mundo (recuérdese el «estornudo» de las Bolsas asiáticas en 1997: las maniobras irregulares de un broker singaporés estuvieron a punto de terminar generando un crack bursátil de proporciones planetarias; no podría pensarse en una ilustración mejor del llamado «efecto mariposa»: una mariposa agita sus alas en Tokyo y, en virtud de los efectos multiplicadores de la interdependencia, produce un terremoto en Nueva York...). Vid. De Sebastián, L., Neoliberalismo global. Apuntes críticos de economía internacional, Trotta, Madrid, 1997, p. 20 y ss. Es interesante, por otra parte, que un corsario de las finanzas tan poderoso como G. Soros (se dice que fue él quien forzó la retirada de la libra esterlina del Sistema Monetario Europeo) venga denunciandoen los últimos tiempos los peligros inherentes a la incontrolabilidad del capital financiero internacional: «La idea del laissezfaire, de que los mercados deberían abandonarse a sus propios mecanismos [...] me parece peligrosa. La inestabilidad de los mercados financieros puede originar serias dislocaciones económicas y sociales». (Soros, G., «Hacia una sociedad abierta global», El País, 23-12-1997).

(11) Citado por Albert, M., Capitalismo contra capitalismo, cit., p. 170.

(12) Petrella, R., «Une même logique inégalitaire sur toute la planète», Manière de VoirLe Monde Diplomatique, n. 18, Mayo, 1993,p.59. La creciente erosión de la soberanía estatal pone decisivamente en entredicho, por supuesto, la viabilidad del Estado asistencial; en efecto, la estrategia welfarista tradicional presuponíala soberanía estatal(de ahíque se hablara, parafraseando a STALIN, de «keynesianismo en un solo país»). El Estado del Bienestar, señala el mismo R. Petrella, «implica la existencia institucional de un sistema estatal-nacional eficaz, es decir, de un poder político capaz de gobernar la economía doméstica» (Petrella, R., El bien común. Elogio de la solidaridad, trad. cast. de M.Puig, Debate, Madrid, 1997,pp.62-63). Es interesante, en este sentido, la observación de U. BECK: «La retórica de los representantes económicos más importantes en contra de la política social estatal [...] deja poco que desear en cuanto a claridad: pretenden, en definitiva, desmantelar el aparato y las tareas estatales con vistas a la realización de la utopía del anarquismo mercantil del Estado mínimo». (BЕCK, U., ¿Qué es la globalización? Falacias del globalismo, respuestas a la globalización, trad. de B. Moreno, Paidós, Barcelona, 1998, p. 17). 
En realidad, se produce una creciente erosión de la soberanía estatal, sobre todo en el terreno económico; los Estados, señalan B. PERRET y G. ROUSTANG, han perdido en buena parte la capacidad de regular sus propias economías (13). Los gobiernos se sienten permanentemente escrutados por los mercados internacionales: saben que cualquier decisión económica que adopten será inmediatamente conocida y analizada por numerosos inversores y especuladores en todo el mundo; saben también que cualquiera de esas decisiones (subida o bajada de los tipos de interés, devaluaciones de la moneda, etc.) puede generar casi instantáneamente flujos de capital masivos (deseables o indeseables) (14). De ahíla afirmación deLUIS DE SEBASTIÁN, según la cual hoy los gobiernos gobiernan fundamentalmente para los mercados financieros: para las famosas agencias de «ratings» que forman la opinión de los operadores («Moody’s», «Standard and Poor»), para los comentaristas financieros de periódicos como el «Financial Times» $\mathrm{o}$ «The Economist», para los consultores financieros como «Nomura» o «Morgan Stanley»...; en definitiva para las selectas instancias que pueden influir en el proceso de formación de expectativas y opiniones sobre la economía de un país (15).

(13) Perret, B. - Roustang, G., L'économie contre la société, Esprit-Seuil, París, 1993, p. 158. No es solamente la noción de soberanía la que resulta cada vez más superada por las circunstancias; también el concepto de democracia, advierte J. EsTEFANíA, puede llegar a verse privado de sentido: ¿para qué votar, si el margen de discrecionalidad del que dispondrá el gobierno que emerja de las urnas será tan reducido? Las diferencias programáticas entre los diversos partidos dejarían de ser relevantes, pues el partido vencedor, sean cuales sean sus credenciales ideológicas oficiales, tendrá que plegarse a lo que exija la coyuntura económica internacional (vid. Estefanía, J., Contra el pensamiento único, Taurus, Madrid, 1997, p. 165 y ss.). En ese sentido, un editorial del influyente Washington Post reconocía recientemente que «los mercados financieros y los bancos centrales que fijan los tipos de interés son ahora los generales en una guerra que dura ya 20 años y que en teoría se justifica como necesaria para controlar la inflación, pero en la práctica vacía al Gobierno de su poder y empobrece la democracia» (Washington Post, 10-12-1995; citado en NAVARro, V., «En contra del determinismo económico», El País, 18-07-1997).

(14) De Sebastián, «Encadenar a tiempo..»., cit., p. 18; vid. también Rösner, H.J., «Globaler Wettbewerb und soziale Sicherung der Arbeitnehmer», en Sozialstaat wohin?, cit., pp. 176-177.

(15) De SEBASTIÁN, L., «Encadenar a tiempo..»., cit., p. 19; actualmente existen seis grandes sociedades de expertos financieros que elaboran clasificaciones (ratings) mundiales periódicas, 
Lo que interesa destacar en relación a nuestro tema es que ese proceso de mundialización o globalización económica parece jugar en contra del Estado social (16). En efecto, la lógica del mercado mundial parece penalizar a los países más civilizados (aquéllos en los que se pagan salarios altos, los que limitan la jornada laboral, los que imponen pesadas cuotas de seguridad social con las que poder financiar prestaciones sociales, los que prohiben el trabajo infantil, etc.) y parece primar a los más «bárbaros» (es decir, a los que admiten el trabajoinfantil, los que permiten salarios de miseria, los que no limitan la jornada de trabajo ni reglamentan prácticamente las condiciones laborales...). De ahí que, en la actualidad, los derechos sociales y las reglamentaciones laborales tiendan a ser vistas como una rémora que encorseta el dinamismo y la capacidad de adaptación de las empresas, como un lastre que hipoteca la competitividad de un país en el mercado mundial (17). Y así, mientras las economías europeo-occidentales, supuestamente lastra-

jerarquizando a los países en base a [lo que esos expertos entienden por] su «salud financiera» y a las perspectivas más o menos atractivas para la inversión. Los gobiernos hacen esfuerzos ímprobos por obtener «buenas notas» ante estos severos examinadores, pues saben que sus dictámenes son muy tenidos en cuenta por los inversores internacionales. R. PETRELLA ha criticado la excesiva opacidad con que son elaboradas esas clasificaciones, poniendo también en duda la fiabilidad «científica» de los criterios en que se basan. Si poseen una influencia tan notable sobre la acción de los gobiernos, su génesis debería ser transparente, y habría de permitirse el debate público sobre los criterios que las fundamentan. Vid. PETRELLA, R., El bien común, cit., p. 141 y ss.

(16) Vid. BöcKer, G., «Sozialpolitik zwischen...»., cit., p. 144; el presidente del Banco Mundial, J.D. WolfEnsoHn, reconocía en 1995 que «la reducción de las intervenciones gubernamentales en los mercados y la creciente integración del comercio y de los flujos de capitales hace que las decisiones que afectan a los salarios y a las condiciones de trabajo sean dictadas por presiones competitivas mundiales» (WORLD BANK, World Development Report 1995: Workers in an Integrating World, Oxford University Press, Nueva York, 1995, p. 5).

(17) La clave del problema podría estribar, quizás, en el hecho de que la globalización económica se encuentre mucho más avanzada que la globalización política e institucional.En el nivel nacional, el poder estatal había sido capaz de corregir en alguna medida las injusticias distributivas y las demás disfunciones y desequilibrios generados por la economía de mercado; pero, en el nivel planetario, faltan por el momento las instituciones supraestatales capaces de encauzar y humanizar a las fuerzas económicas. «No disponemos-señala al respecto G. Sorosde instituciones internacionales adecuadas para la protección de las libertades individuales, los derechos humanos y el medio ambiente, o para el fomento de la justicia social [...] Esas instituciones existen en países concretos, pero no en la sociedad global [mundial]. El desarrollo 
das por los costes sociales, vienen creciendo a un ritmo del $2 \%$ o el $3 \%$ anual, las dinámicas economías asiáticas (sobre todo las de la cuenca del Pacífico), liberadas desde un principio de «anticuados» tabúes como la prohibición del trabajo infantil o la imposición de un salario mínimo, crecen a un ritmo entre dos y tres veces superior (18).

Las empresas transnacionales (que son los verdaderos global players, los únicos sujetos económicos capaces de adaptarse a la mundialización de los mercados y también los más beneficiados por ella) refuerzan ese proceso al concentrar crecientemente sus actividades en aquellos países en los que la presión fiscal y los costes sociales son menores, en los que la mano de obra es más barata, en los que los sindicatos poseen poca influencia y en los que las reglamentaciones laborales son más laxas. Se trata del conocido fenómeno de las «deslocalizaciones»: las fábricas, por ejemplo, son trasladadas desde países desarrollados (en los que abundan las incómodas «rigideces» sociales y laborales) a países del Tercer Mundo en los que existe una reserva inagotable de mano de obra dispuesta a trabajar por salarios miserables y a aceptar cualesquiera horarios y condiciones laborales. Citemos algunas cifras: el coste medio actual de una hora de trabajo en industrias de transformación es de 21'53 dólares en Alemania, 14'77 en USA, 3'95 en Taiwan, 2'64 en Brasil y 0’31 en Sri Lanka... (19). A la vista de esas abismales diferencias, se comprende que las multinacionales se muestren dispuestas a

de una sociedad global se ha quedado retrasado respecto al de una economía global» (Soros, G., «Hacia una sociedad abierta global», El País, 23-12-1997). En un sentido parecido se pronuncia U. BECK: «La sociedad mundial sin Estado mundial significa una sociedad no organizada políticamente en la que surgen nuevas oportunidades de acción y de poder para actores transnacionales democráticamente no legitimados» (BЕск, U., ¿Qué es la globalización?, cit., p. 50). Los «actores» a los que se refiere BECK son, claro está, las grandes compañías transnacionales, que han sabido adaptarse a la globalización mucho más rápidamente que los Estados: ellas son los genuinos global players.

(18) Vid. RöSNER, H.J., «Globaler Wettbewerb..»., cit., p. 175.

(19) Datos en Julien, C., «Ces «élites» qui régnent sur des masses des chômeurs», Le Monde Diplomatique, Abril, 1993, p. 9; el problema del dumping social y de las deslocalizaciones es complejo y susceptible de otro tipo de consideraciones. Algunos economistas estiman que los costes salariales inferiores son la única «ventaja comparativa» de que gozan los países pobres en la competición económica internacional (en todos los demás aspectos-tecnología, merchandising, etc, se hallan en clara desventaja), y que, por tanto, sería injusto no permitirles hacer uso de ella. Vid. De Sebastián, L., Neoliberalismo global, cit., p. 43 y ss. 
afrontar las considerables inversiones que conllevan las «deslocalizaciones», en la seguridad de que podrán amortizarlas rápidamente con lo que ahorrarán después en salarios y en cotizaciones sociales. El «Financial Times» explicaba hace poco cómo la «General Motors», desde la firma delNAFTA, viene clausurando muchas de sus fábricas en EEUU y Canadá para abrir otras en México; la misma empresa ha decidido instalar una planta de montaje en territorio de la antigua Alemania Oriental, porque allí [cito al propio «Financial Times»] «los empleados están dispuestos a trabajar más horas que sus mimados compañeros de la Alemania Occidental» [por el 40\% del salario de éstos] (20). De esa forma se va extendiendo lentamente la idea de que los derechos sociales son un lujo inmerecido e insostenible, al que los «mimados» trabajadores occidentales deberán ir pensando en renunciar.

\section{Estado social y «fin de la sociedad del trabajo»}

Existe, finalmente, un aspecto que aquí sólo podemos evocar muy superficialmente (si lo tratáramos más a fondo, ocuparía toda la disertación): me refiero a la relación entre el Estado social y el problema del desempleo. La aspiración al pleno empleo fue, desde luego, uno de los rasgos definitorios del Estado social desde sus comienzos, y algunas sociedades europeas disfrutaron prácticamente de una situación de pleno empleo durante los idílicos años 50 y 60. Desde los años 70, sin embargo, nuestras sociedades se ven corroídas por un desempleo estructural que progresa como un tumor maligno: la automatización y el progreso tecnológico hacen cada vez más superflua a la «fuerza de trabajo» humana; de esa forma, un porcentaje cada vez más amplio de personas son definitivamente expulsadas del sistema productivo. El carácter estructural de la destrucción de empleo se ve confirmado por el hecho de que las fases de reactivación económica ya no consiguen hacer retroceder al desempleo (o lo consiguen en muy escasa medida); la bonanza económica ya no es sinónimo de creación de empleo: de ahí que los economistas hayan acuñado la expresión jobless growth para designar al modelo actual de crecimiento económico (la producción puede crecer muy rápidamente sin que ello se traduzca en generación de empleo). Por eso algunos sociólogos (A. GORZ, por ejemplo), dando por supuesto que el desempleo creciente es un

(20) Citado por Сномsкy, N. , «Los amos del universo», El País, 28-04-1993. 
fenómeno ya irreversible, sostienen que es preciso empezar a pensar la sociedad «post-laboral», una sociedad que diferirá radicalmente de la «sociedad del trabajo» a la que estamos acostumbrados (21).

(21) Gorz, A., Métamorphoses du travail, quête du sens. Critique de la raison économique, Galilée, París, 1988; Gorz sostiene la necesidad de abordar la transición a la sociedad postlaboral (que ha de llegar de todas formas, como lo demuestra la creciente desconexión entre el crecimiento económico y la generación de empleo) en forma racional y ordenada. Defiende la «necesidad de una nueva perspectiva que rompa con la ética del trabajo y con la utopía del trabajo», pues «ambas están privadas de sentido en un mundo en el que el trabajo humano no es ya la principal fuerza productiva y en el que, por tanto, no habrá ya empleos permanentes para todas las personas: [...] la economia ya no necesita, y necesitará cada vez menos, el trabajo de todos». (Métamorphoses du travail, cit., p. 93). La transición hacia el post-trabajo ha comenzado ya en los hechos, pero en forma injusta y caótica; de momento, se ha traducido en una inquietante dualización de la sociedad: de un lado, el grupo de «privilegiados» que todavía disfruta de empleos fijos a tiempo completo; del otro, la masa creciente de parados, precarios y subempleados (op. cit., p. 86). Los primeros se aferran a sus privilegios; los segundos permanecen hasta ahora desorganizados, pues no se sienten representados por las organizaciones sindicales tradicionales. La transición armónica hacia la sociedad post-laboral, estima Gorz, sólo podrá conseguirse mediante alguna fórmula de «redistribución del trabajo» (del poco trabajoque vaya quedando) y mediante la invención de modalidades no-laborales de integración social.

En un trabajo más reciente, U. BECK expresa inquietudes similares a las de GoRz: «¿Se ha quedado sin trabajo la sociedad del trabajo? (...) La productividad aumenta en una medida tal que podemos producir cada vez más bienes con menos trabajo (...) El paro ya no es un destino marginal: nos afecta potencialmente a todos, y también a la propia democracia como forma de vida (...) Loque se ha presentado como un remedio-laflexibilización del mercadolaboral-nohahecho más que ocultar la terrible enfermedad del paro; no la ha curado en absoluto (...) Hay que volver a cimentar el futuro de la democracia más allá de la sociedad del trabajo «(BECK, U., ¿Qué es la globalización?, cit., pp. 92 - 93). H.P. MARTIN y H. SCHUMANN, por su parte, manejan la hipótesis de una sociedad 20:80 (20\% de activos, $80 \%$ de desempleados) para el siglo XXI: «En el próximo siglo, el $20 \%$ de la población activa bastará para mantener en marcha la economía mundial» (Martin, H.P. - Schumann, H., La trampa de la globalización, trad. de C. Fortea, Taurus, Madrid, 1998, p. 10). El principal problema estribará, entonces, en cómo mantener distraído al 80\% económicamente superfluo. Z. BRZEZINSKI ha acuñado, en relación con este problema, el neologismo tittytainment (resultado de la fusión de tits y entertainment): la solución debería combinar una oferta abrumadora de espectáculos y posibilidades lúdicorecreativas (que mantendría «entretenidos» a los desempleados) con la cobertura de sus necesidades básicas por parte del Estado (de esta forma, se está postulando, curiosamente, una reediciónampliadadelEstadoasistencialoEstado-nodriza: de ahíla sorprendentemetáforamamaria (tits significa pechos femeninos...). Vid. La trampa de la globalización, cit., pp. 11 y ss. 
Bien, lo que nos interesa a nosotros es que algunos analistas ven la causa principal del desempleo, no en la automatizacion de la producción, sino (¡cómo no!) en las políticas del Estado social. De un lado, las cotizaciones sociales demasiado elevadas harían muy gravosa para los empresarios la creación de nuevos puestos laborales. Se daría así una paradójica contradicción entre el Derecho del trabajo y el derecho al trabajo: la única forma de satisfacer el derecho al trabajo (es decir, la única forma de estimular la creación de empleo) consistiría en desregular los salarios, permitir el despido libre y aligerar o suprimir las cotizaciones sociales (es decir, desmantelar elDerecho del trabajo) (22). Es sabido que los economistas de la escuela neoclásica ven la única causa del desempleo en los salarios demasiado altos: el Estado intervencionista, con su torpe paternalismo, mantiene el precio del factor trabajo en niveles artificialmente elevados. En un mercado de trabajo plenamente desreglamentado, en el que la fijación de los salarios se confiase exclusivamente a la oferta y la demanda (sin topes «artificiales» como el salario mínimo...), el desempleo, según esas teorías, sería progre-

(22) Roustang, G. - Perret, B., L’économie contre la société, cit., pp. 106-107. Esa antítesis entre el derecho al trabajo y el Derecho del trabajo parecería venir confirmada por los desiguales resultados que en materia de lucha contra el desempleo vienen cosechando Europa y los EE.UU.: estos últimos, con un mercado laboral mucho más desreglamentado y con cargas sociales mucho más livianas para los empleadores, exhiben en este momento una tasa oficial de desempleo inferior al $5 \%$, en tanto que la tasa europea supera el 10\%. Ocurre, sin embargo, que las estadísticas laborales norteamericanas son elaboradas con criterios muy peculiares: para ser considerado «empleado», basta con haber trabajado una sola hora (remunerada) en la semana precedente; así, el $48 \%$ de los escolares son computados entre la población activa (es frecuente que los estudiantes realicen pequeños trabajos por horas) (datos en UCHITELLE, L., «How the Job Count is Off», The New York Times, 7-11-1993). El propio (ex)ministro de trabajo R. REICH reconocía en 1993 que esas estadísticas triunfales son «groseramente inexactas» (citado por CALABresi, M., «Jobs in an Age of Insecurity», Time, 22-11-1993). Por otra parte, la condición social de los parados europeos es, en bastantes aspectos, mejor que la de muchos subempleados norteamericanos, mal pagados y prácticamente privados de derechos sociales y laborales (son los llamados working poor). Sobre el tema, vid. HALIMI, S., «Comment expliquer les millions d'emplois créés?», Manière de Voir-Le Monde Diplomatique, n. 16, Octubre 1992, p. 34; ToInet, M.F., «Emplois flexibles, société en miettes», Manière de Voir-Le Monde Diplomatique, n. 31, Agosto 1996, p. 58. (En Estados Unidos circula últimamente este chiste, quizá no muy hilarante pero síilustrativo de la situación actual: «iquébien!», dice alguien, «BillClinton ha conseguido crear millones de nuevos trabajos»; «ien efecto!», contesta otro, «yo tengo tres de esos trabajos y no me alcanzan para dar de comer a mi familia»). 
sivamente reabsorbido (23).

Otro argumento tradicional de los enemigos del Estado del Bienestar es que las prestaciones sociales demasiado generosas se convierten en un factor de desincentivación laboral: los asistidos se instalan en una actitud «lactante», se dejan cuidar y alimentar por el Estado-nodriza, en lugar de ganar el pan con el sudor de sus frentes. El Estado social fomentaría, así, la holgazanería y el parasitismo (24).

(23) Vid. WALwEI, U., «Mehr Beschäftigung durch Umbau des Sozialstaats?», en Sozialstaat wohin?, cit., p. 24.

(24) Vid. WALWEI, U., «Mehr Beschäftigung..»., cit.,p. 18; BÖCKER, G., «Sozialpolitik..»., cit., p. 152; Hansen, V., «Sozialstaat vor dem Umbau..»., cit., p. 127; este tipo de efecto contraproducente (supuestamente generado por la asistencia social) es a veces designado con la expresión «trampa de la pobreza» (poverty trap): los asistidos quedan estigmatizados, se perciben a sí mismos como parásitos, pierden la confianza en sí mismos; en lugar de ayudarles a reincorporarse a la sociedad, la asistencia social los confina definitivamente en el círculo vicioso de la marginalidad y la dependencia (vid., por ejemplo, GofFMAn, E., Stigma: Notes on the Management of Spoiled Identity, Penguin, Harmondsworth, 1968). Si prestamos crédito a algunos críticos neoconservadores, casi parecería, observa irónicamente R. PETRELLA, que el aumento de la pobreza se debiera... ; a la existencia del Estado asistencial (nacido para erradicar la pobreza)! (El bien común, cit., pp. 57-58). Así, para R. RECTOR, estrella de los think tanks y considerado como una especie de «contraministro» de Asuntos Sociales en EE.UU., elEstadoprovidencia resulta ser la causa de la mayor parte de los problemas sociales: la asistencia pública, según él, «subvenciona comportamientos destructivos y asociales: cuanto más se gasta [en programas sociales], más se debilita laética del trabajo, más se multiplica el númerodenacimientos extramatrimoniales, lo cual a su vez es el factor principal que explica otros problemas, desde el fracaso escolar a la delincuencia, pasando por el desempleo y los desórdenes afectivos ( (declaraciones a The Wall Street Journal, 23-01-1995). M. REED, dirigente de la muy influyente Christian Coalition, considera que la sociedad ya ha concedido demasiadas oportunidades a los pobres: «La gente está harta de tanto gimoteo en relación con los pobres. Los contribuyentes de clase media consideran que pagan cada vez más [impuestos] para los pobres, y que éstos no dejan de comportarse cada vez peor» (Harper's Magazine, Marzo 1995). Este tipo de ideas están muy extendidas entre las bases del Partido Republicano; la mayoría republicana en el Congreso consiguió en 1996, por ejemplo, la aprobación de recortes sustanciales en la ayuda federal a las madres solteras (vid. ToINET, M.F., «Aux sources puritaines de la pensée réactionnaire», Manière de Voir-Le Monde Diplomatique, n. 31, Agosto 1996, p. 58 y ss., así como Halimi, S., «Les boîtes à idées de la revanche sociale», en el mismo número, p. 46 y ss.). 


\section{Fatalismo economicista: ¿final de la Política?}

Bien, como resumen, cabe señalar que, según hemos visto, la mayor parte de los reproches dirigidos al Estado social son de carácter económico. Esto hubiera sorprendido tanto a KEYNES como a BEVERIDGE o a HELLER, los cuales pensaron siempre que el reconocimiento de los derechos sociales y la construcción del Estado social favorecerían el desarrollo económico (25): ellos nocreían en esa antítesis de fondo entre eficiencia económica y justicia social (que es la idea que parece subyacer en las críticas liberales actuales: no se puede tener todo; hay que escoger entre la justicia y la productividad, entre una sociedad igualitaria pero pobre y una sociedad rica pero muy desigual). KEYNES y BEVERIDGE pensaron que era posible domesticar el sistema de mercado, corregir sus disfunciones, enmendar sus consecuencias sociales más indeseables (pobreza, desigualdad extrema), todo ello dentro de un marco básicamente capitalista (eso proponía también la escuela de la «economía social de mercado» [soziale Marktwirtschaft] o «escuela de Friburgo»: un capitalismo «civilizado», un capitalismo «con rostro humano», moderado por la intervención estatal). Los críticos liberales actuales, en cambio, parecen presuponer que el sistema de mercado es un «todo» indescomponible, no susceptible de reparaciones quirúrgicas: si jugamos al juego capitalista, hemos de aceptar todas sus reglas y todos sus resultados (incluso aquellos que nos parezcan moralmente rechazables). Esos resultados incluyen la existencia de ganadores y perdedores; el Estado, al amortiguar la derrota de los perdedores (mediante prestaciones sociales) y al enturbiar (mediante «confiscaciones» fiscales) la victoria de los ganadores, lo que hace es desnaturalizar el juego, poniendoen peligro sucontinuidad.

A mi modo de ver, esa concepción del sistema de mercado como un «orden natural» (Kosmos en la terminología de HAYEK), con sus leyes inmanentes y sus mecanismos intocables, supone una peligrosa forma de fundamentalismo. Muchas de las opiniones actuales sobre el futuro de Estado social parecen informadas por una especie de fatalismo economicista: quizás se reconozca que el Estado social es más civilizado, más justo, más democrático que cualesquiera modelos alternativos pensables; pero todas esas consideraciones son fulminadas por el economista (el portavoz del «principio de realidad»),

(25) Vid. Mishra, R., The Welfare State in Crisis, Harvester, Londres, 1985, p. 7 y ss. 
que se reserva el derecho a decir la última palabra: «sí, pero, desgraciadamente, el Estado social es económicamente disfuncional» («ergo», está condenado a desaparecer, pues así lo prevén las inflexibles leyes económicas). Y, entonces, el filósofo, el politólogo, el moralista (todos los que antes habían demostrado la superioridad del Estado social desde el punto de vista moral, histórico, sociológico, etc.) callan, paralizados por una especie de temor reverencial hacia esa sabiduría hermética y superior de la que el economista se dice portador. Los economistas se comportan cada vez menos como científicos (que pergeñan hipótesis cautas, modelos provisionales, «falsables» [refutables] por los hechos) y se parecen cada vez más a la sibila de Delfos: ellos escrutan las arcanas e intocables leyes económicas, y después anuncian su oráculo a la masa de creyentes: el Estado social debe ser desmantelado, pues así lo exige la diosa «competitividad» (o el dios «mercado») (26).

B. ROUSTANG y G. PERRET (en una obra reciente cuyo título es precisamente L'Économie contre la Société) han analizado con gran lucidez los progresos de ese reduccionismo economicista, que parece haber embotado las mentes de muchos de nuestros contemporáneos. Según ellos, la ciencia económica (o, más genéricamente, la mentalidad economicista) transgrede cada vez más los límites naturales de su jurisdicción, tendiendo a «colonizar» otras esferas de la vida social

(26) En opinión de I. RAMONET, el fatalismo economicista, disfrazado de «realismo» y «pragmatismo», es la verdadera entraña del llamado pensamiento único (RAMONET, I., Un mundo sin rumbo, Debate, Madrid, 1996, p. 112). En realidad, el determinismo economicista era tradicionalmente una de las señas de identidad del...jmaterialismo histórico!..Esta inopinada afinidad filosófica entre neoliberalismo y marxismo (extrema se tangunt) ha sidoingeniosamente subrayada por E. LAMO DE EsPINOSA en un artículo reciente («Marxismo burgués», El País, 501-1998). Ya en 1935 había afirmado JULIÁN BESTEIRO que «hay gran número de adversarios del marxismo que [...] emplean en la práctica el método materialista de la Historia». La idea según la cual los factores económicos (la base, la estructura) son el principal resorte explicativo de una sociedad (todo lo demás -la política, el Derecho, las ideas.., es mera «superestructura»: reflejo, epifenómeno, sombra de lo económico), dogma central del marxismo, parece hoy haber sido heredada por los neoliberales, bajo nuevas formas. Otro tanto cabría decir del antiestatalismo: si para los marxistas el Estado era un instrumento de dominación, que terminaría siendo abandonado en el desván de la Historia, «junto a la rueca y el hacha de bronce», para los neoliberales el Estado, como sabemos, es ese poder asfixiante, despilfarrador e ineficaz, que distorsiona la lógica de la economía de mercado y coarta la creatividad y el dinamismo de la sociedad civil... 
y otros órdenes valorativos, como la política o la cultura (27). Son conocidos los debates actuales acerca de la aplicabilidad de los criterios de mercado a la vida cultural (por ejemplo, salta a la vista que la competencia empresarial entre las televisiones ha conducido en pocos años a una aberrante degradación de la calidad de los contenidos y a la «dictadura delíndice de audiencias»). La economización de la política, por su parte, consiste en la reducción del debate político a la gestión económica a corto plazo. En relación con cualesquiera problemas, los aspectos tomados en consideración son exclusivamente los de la repercusión inmediata sobre el crecimiento económico: es bueno o racional todo lo que favorece el desarrollo económico; es malo o irracional todo lo que entorpece el desarrollo. Todos losdemásaspectos(los relativos a lajusticia, lacuestión de lapropiadeseabilidad del crecimiento económico como un fin en sí mismo, la cuestión de la sostenibilidad delcrecimiento: nuestraposibleresponsabilidad moral frente a generaciones venideras [siel crecimiento incontroladoesquilma irreparablemente recursos naturales insustituibles] y frente a las masas empobrecidas de los países del Tercer Mundo...) son sistemáticamente preteridos o relegados a un segundo plano.

\section{Cómo el colapso del «socialismo real» ha espoleado al fundamentalismo liberal}

Antes me refería a la creencia en la validez suprahistórica e inflexible de las «leyes del mercado» como una forma de fundamentalismo. I. SOTELO ha escrito que «lo que caracteriza a cualquier tipo de fundamentalismo es la reducción de la enorme complejidad del mundo a una propuesta simple, que tendría el don de resolver todos los problemas que tenemos planteados los humanos» (28). Creo

(27) Roustang, B. - Perret, G., L'économie contre la societé, cit., p. 165 y ss.; M. BeAud, por su parte, considera que el espíritu de la época se caracteriza por un doble reduccionismo: lo político es reducido a lo económico, y lo económico es reducido a lo financiero. «La economía domina a las sociedades. En relación con numerosas cuestiones, que en otros tiempos hubiesen sido tratadas en términos políticos o éticos, predominan hoy las consideraciones económicas [...] Las sociedades [son] cada vez más dependientes de la economía; y las economías [son] cada vez más tributarias de las tensiones y sobresaltos de una esfera monetario-financiera mundial cuya dinámica nadie está en condiciones de controlar [...]» (BEAUD, M., «Le basculement du monde», Manière de Voir-Le Monde Diplomatique, n. 28, Noviembre, 1995, p. 75).

(28) Sotelo, I., «El fundamentalismo liberal», El País, 17-12-1994. 
que algunos ultraliberales actuales participan de esa ingenuidad simplificadora característica de los fundamentalismos; la panacea liberal, como sabemos, sería la desregulación, lajibarización delEstado (y de «lo público»en general): eliminar todas las cortapisas políticas y legales que impiden que la «mano invisible» del mercado obre las maravillas de las que es capaz (olvidan que el mismo A. SMITH reconoció que «la mano invisible del mercado acabaría con la posibilidad de una existencia humana decente, si el gobierno no adoptara ciertas medidas para evitarlo») (29).

Gran parte del atractivo del ultraliberalismo estriba, sin duda, en esa sencillez, en esa rotundidad; como señala M. ALBERT, el modelo neoliberal ofrece la ventaja de brindar una sola idea sólida y transparente («el mercado es bueno, el Estadoes malo»), un dogma o conjunto de dogmas «tan tranquilizador como podía serlo, antiguamente, el catecismo marxista» (30).

R. PETRELLA ha diseccionado ingeniosamente la retórica y los sobreentendidos de la nueva «ortodoxia» político-económico-ideológica en un artículo titulado «Elevangelio de la competitividad» (31). Según él, en cada época histórica

(29) Citado por Álvarez Puga, E., «La ciudadanía, indefensa frente a una interesada representación de la realidad», Cuatro Semanas, Junio, 1993, p. 6.

(30) Albert, M., Capitalismo contra capitalismo, cit., p. 182.

(31) Petrella, R., «L'évangile de la compétitivité», Manière de Voir-Le Monde Diplomatique, n. 18, Mayo, 1993,p. 14 y ss.; PeTRELla sintetiza en estos términos el núcleo dogmático de esta nueva «religión»: «Estamos comprometidos en una guerra industrial, tecnológica y económica sin cuartel a escala mundial. El objetivo es sobrevivir. La supervivencia supone competitividad; fuera de ésta no hay salvación, no hay crecimiento ni bienestareconómico y social [...] El mundo se compone de una serie de mercados por conquistar. El largo plazo no existe: lo que importa es ganar ahora» (El bien común, cit., p. 82). P. KRUGMAN, economista con aureola iconoclasta pero muy respetado en su gremio, estima urgente revisar y desmitificar el concepto de «competitividad», y considera unilaterales y falaces los criterios utilizados en la elaboración del ranking internacional de competitividad que propone anualmente el World Economic Forum (Krugman, P. , «Competitiveness: A Dangerous Obsession», Foreign Affairs, Marzo-Abril, 1994, p. 28 y ss.). También A. Pfaller, I. Goughy G. THERBorn, tras una minuciosainvestigación empírico-comparativa acerca de la relación entre los niveles de protección social y los niveles de competitividad económica en cinco países desarrollados, concluyen que es preciso reformularel concepto de competitividad. Más concretamente, proponen distinguir entre dos modalidades de competitividad: competitividad aparente y competitividad subyacente. La primera podría definirse como «la capacidad para vender productos en un mercado altamente competitivo». La competitividad aparente «es el resultado de los precios y de la calidad relativa del producto en 
hay palabras o conceptos que, al suscitar una unanimidad casi absoluta, legitiman automáticamente todo lo que tocan; en nuestro tiempo juega ese papel el concepto de «competitividad». El elogio supremo que hoy puede hacerse de un trabajador, de una empresa, de una organización o de un país consiste en decir que son «competitivos». El culto de la competitividad tiene sus oficiantes y sus teólogos; hoy día existen auténticos «especialistas en competitividad» que inician al público en sus misterios a través de libros con títulos como «A la búsqueda de la excelencia», «Escuela de triunfadores», etc. Gracias a ellos, hemos aprendido que la competitividad no es una categoría que se circunscriba a lo económico, sino que es una especie de imperativo metafísico que debe informar cada pliegue de nuestras vidas: la competitividad no sólo se predica de las empresas («microcompetitividad»), de los sectores industriales («mesocompetitividad») o de países o continentes enteros («macrocompetitividad»), sinotambién de los sistemas educativos (cuya finalidad, obviamente, no debe ser otra que la capacitación de profesionales muy competitivos...), de los sistemas sanitarios y asistenciales, de los medios de comunicación, de la creación artística...

Probablemente, uno de los factores que explican los rápidos progresos del fundamentalismo liberal es el estrepitoso fracaso histórico y rápida descomposi-

comparación con productos extranjeros. Es un concepto apropiado para las empresas. El aligeramiento de costes, incluyendo el del trabajo, es, desde esta perspectiva, un activo a la hora de competir, ya que facilita la fijación de precios competitivos». Ahora bien, la noción de competitividad aparente es aplicable a la comparación entre empresas, pero no a la comparación entre países; cuando se trata de estos últimos, el concepto a utilizar debería ser el de competitividad subyacente (que podríamos definir como la capacidad de un país para defender sus cuotas de mercado sin dejar de garantizar por ellounos salarios dignos y unos derechos sociales y laborales amplios a sus ciudadanos): «Para un país las cosas son diferentes. De la misma forma que no tendría sentido denominar «competitiva» a una empresa que tiene beneficios bajos o nulos, tampoco tiene sentido considerar como una ventaja competitiva el que la fuerza laboral de un país reciba permanentemente ingresos inferiores que en otros países. Sería más apropiado decir que ese país no puede permitirse que sus trabajadores reciban ingresos más elevados porque no es suficientemente competitivo [...] Lainsuficiente competitividad subyacente es la que puede forzar a un país a recortar los elevados costes de mantenimiento del Estado benefactor para defender su competitividad aparente». (Pfaller, A. -Gough, I. - Therborn, G. (comp.), Competitividad económica y Estado del Bienestar. Estudio comparativo de cinco países avanzados, trad. de R. Muñoz de Bustillo, Publicaciones del Ministerio de Trabajo y Seguridad Social, Madrid, 1993, pp. 29-30). 
ción del modelo socio-económico que había funcionado como antagonista e hipotética alternativa al capitalismo a lo largo de la mayor parte del siglo XX: el socialismo de Estado, el comunismo soviético (32). Debe recordarse que la legislación de protección social puede ser interpretada, desde cierto punto de vista, como una estrategia del capital dirigida a «comprar» la mansedumbre de los trabajadores mediante concesiones socio-económicas diversas e impedir que fuesen seducidos por el modelorival, por laideología comunista. El hundimiento del comunismo significa que ya no existe un rival amenazador, ya no existen alternativas (hemos entrado en la era del «pensamiento único», del «modelo único», de la «única política económica posible»...). El capital, por tanto, al no sentirse presionado por la competencia de un modelo antagonista, puede estimar que la vieja estrategia anti-revolucionaria (asegurarse la lealtad de los trabajadores por medio de concesiones sociales) resulta ya superflua, porque el peligro de una revolución ha desaparecido definitivamente del horizonte. Esa sería una de las razones que explicarían la actual ofensiva contra el Estado social, comoha señalado (entre otros) R. MUÑOZ DE BUSTILLO (33). Diríamos que la existencia del comunismo garantizaba, al menos, una saludable competencia entre modelos de sociedad diversos; ahora, en cambio, hemos desembocado en una situación de «monopolio» político-ideológico a escala mundial, y eso nos acarrea las perversiones características de las situaciones de monopolio (perversiones que, por cierto, los liberales conocen y explican muy bien...).

Otro factor a considerar es que el gigantesco fracaso comunista, en cierto modo, ha proyectado una sombra deslegitimadora sobre el conjunto de la izquierda, incluyendo a la izquierda socialdemócrata que hasta ahora venía defendiendo al Estado social. Por un curioso mecanismo de asociación mental, todas las ideas y realidades que guardasen un parentesco, próximo o remoto, con el aborrecido comunismo, todas las referencias que portasen una etiqueta, no ya comunista, sino «socialista» o simplemente «social», parecen haber quedado bajo sospecha. Valores como la igualdad, instituciones como la seguridad social, funciones

(32)Las implicaciones socio-políticas a nivel mundial del colapso comunista son analizadas con rigor en BlackBuRn, R. (ed.), Después de la caída. El fracaso del comunismo y el futuro del socialismo, trad. de A. Ferrero, Crítica, Barcelona, 1993.

(33) MuÑoz DE Bustillo, R., «¿Por qué está en cuestión el Estado de Bienestar?», Temas para el Debate, n. 24, Noviembre, 1996, p. 30. 
estatales como la imposición fiscal o la planificación económica, movimientos sociales como el sindicalismo, referencias ideológicas como la social-democracia...; todas ellas han quedado decisiva e injustamente salpicadas por la hecatombe comunista (como si W. BEVERIDGE oH. HELLER hubiesen tenido algo que ver con STALIN...). «Hoy -escribe M. ALBERT- la sensibilidad de izquierdas se encuentra huérfana, castigada, privada de sus referencias y de sus certezas; lanzada, en suma, hacia las tinieblas del fracaso histórico» (34).

\section{7. «Capitalismo neoamericano» frente a «capitalismo renano»}

Recurriendo al chascarrillo anglosajón, diríamos que el peligro actual estriba en que podamos «tirar al niño con el agua del baño»: que, al deshacernos del agua sucia del totalitarismo comunista, se escurran también por el desagüe de la Historia las valiosas conquistas sociales vinculadas al Estado del Bienestar. Se trata de un peligro real, que ha sido analizado recientemente por M. ALBERT en una enjundiosa obra titulada «Capitalismo contra capitalismo». Según ALBERT, el hundimiento del comunismo, lejos de representar el «fin de la Historia», supone la apertura de un nuevo combate ideológico que opondrá entre sí, no ya al capitalismo con el comunismo, sino a dos modelos de capitalismo, a los que ALBERT llama «modeloneoamericano» $\mathrm{y}$ «modelo renano» (35). El capitalismo «neoamericano» encuentra su mejor expresión, obviamente, en los EE.UU. actuales, y se basa, según ALBERT, «en el éxitoindividual y el beneficiofinanciero a corto plazo». El modelo renano (que se ha desarrollado en países como Suiza, Holanda, Austria, Suecia y, sobre todo, Alemania) se basa, por el contrario, en el consenso, el bienestar colectivo, la preocupación por el largo plazo y la búsqueda del equilibrio entre la eficiencia económica y la justicia social.

El análisis que ofrece ALBERT sobre la situación actual de los EE.UU. es sumamente aprovechable parael debate sobre las virtudes y defectos delEstado social. $\mathrm{El}$ «modelo neoamericano» es el resultadodel «giroliberal» que imprimieronal país las Administraciones republicanas de los años 80: desregulación, recorte de servicios sociales, regresión en la progresividad fiscal (suavización de lapresión fiscal sobre los más ricos), repliegue del Estado... Del análisis a que ALBERT somete al «modelo

(34) Albert, M., Capitalismo contra capitalismo, cit., p. 186.

(35) Albert, M., op. cit., p. 21 y ss. 
neoamericano», nos interesa especialmente lorelativoa las instituciones asistenciales. Naturalmente, supondríauna exageraciónhablarde inexistenciaabsolutadeun sistema asistencial en los EE.UU.; en estos temas, hay que razonar siempre en términos comparativos. Y bien, es perfectamente objetivo afirmar que los derechos sociales se encuentran mucho menos desarrollados en EE.UU. que en Europa occidental.Por ejemplo, EE.UU. es el único país rico del mundo que carece de un sistema universal de atención sanitaria. Subsisten los programas asistenciales MEDICARE (para personas ancianas) y MEDICAID (para personas que viven por debajo del umbral de pobreza), que fueron introducidos en los años 60 por las administraciones demócratas de KENNEDY y JOHNSON. Pero una fracción importante de la población no se beneficia de esa protección: según estadísticas de la propia Administración norteamericana, 41 millones de ciudadanos carecen actualmente de cualquier seguro de enfermedad, y 22 millones más poseen una cobertura sanitaria insuficiente(36). En realidad, el sistema sanitarioestadounidensees primordialmente privado, y se basa en compañías aseguradoras del tipoH.M.O.(HealthMaintenance Organisations), que ofrecen una gama más o menos amplia de servicios a cambio del pago de una prima anual (37). El resultado de esa «mercantilización» de la salud (ese abandonode la atención sanitaria a la lógica del mercado) es, como cabría esperar, una extrema dualización: unos hospitales magníficos (los mejores del mundo) para aquellos que pueden costeárselos, y unaatención sanitaria mediocree insuficiente para los estratos más pobres de la población. Eso explica que, por ejemplo, la tasa de mortalidad infantil en EE.UU. sea un 50\% más elevada que la española (9 por mil en EE.UU.,6 6or mil en España)(38), que las tasas de vacunación norteamericanas sean inferiores en un $40 \%$ a la media de los demás países industrializados, que la tasa de embarazos de adolescentes sea 10 veces más elevada que la de Japón (39), etc.

En el sistema educativo norteamericano descubrimos un dualismo similar: las universidades privadas U.S.A. son, sin duda, las más prestigiosas del mundo (más

(36) Datos en Burgess, F., «Les lobbies contre la santé», Manière de Voir-Le Monde Diplomatique, n. 31, Agosto, 1996, p. 64 y ss.

(37) «Para la mayor parte de los americanos, la salud es una mercancía (commodity) que se compra, y el enfermo es un «cliente» que debe pagar», BuRGESS, F., «Les lobbies contre la santé», cit., p. 64.

(38) Datos en VV.AA., El estado del mundo, 1995. Anuario económico y geopolítico mundial, Akal, Madrid, 1995, p. 62.

(39) Datos en Albert, M, op. cit., p. 55 y ss. 
de un tercio de los artículos científicos que se publican anualmente en todo el mundo son escritos en universidades norteamericanas). Pero esa esplendorosa enseñanza superior (reservada a las élites) coexiste con un sistema escolar muy mediocre en los niveles primarios y medios (40). Esta situación ha permitido afirmar a M. MORISHIMA, uno de los grandes economistas actuales, que «los EE.UU. están en declive y deben volver a pensaren su propio futuro, precisamente por haber olvidado la educación pública, basándolo todo en la privada» (41).

Este fenómeno de dualización es, finalmente, predicable de la sociedad en su conjunto. ALBERT llega a hablar de «apartheid económico»: la sociedad norteamericana «se mueve definitiva y cruelmente en dos velocidades»; es «una sociedad donde las diferentes categorías de población viven, de hecho, en dos planetas distintos que cada año se alejan un poco más uno del otro» (42). Y esa dualización fue considerablemente agudizada por las políticas ultraliberales de los años 80 .

Citemos sólo algunas estadísticas. En EE.UU., el $1 \%$ más rico de la población posee más del $40 \%$ de la riqueza nacional (43). Pese a poseer una de las rentas per capita más altas del mundo, la población norteamericana cuenta con un $17 \%$ de pobres (si definimos como pobres a los que disponen de ingresos inferiores al $50 \%$ del promedio nacional; por buscar una comparación, si aplicamos ese mismo criterio a las sociedades alemana y escandinava, éstas resultan tener sólo un 5\%

(40)El40\% de los escolares norteamericanos alcanza los 18 años sin saber leer correctamente (una situación reflejada con ácido humor en la novela de ToM Wolfe La hoguera de las vanidades); más del $50 \%$ de los norteamericanos adultos son incapaces de ubicar correctamente Gran Bretaña, Francia o Japón en un mapa; datos en Albert, M., op. cit., p. 54.

(41) Morishima, M., «Desde Confucio a Marx, pasando por Weber», en PIRANI, M.(ed.), El futuro de la economía, trad. de M. Barea, Encuentro, Madrid, 1995, p. 91.

(42) Albert, M., op. cit., p. 47 y ss.

(43) Datos en MoncadA, A., «El falso paraíso», El Mundo, 4-11-1996. El porcentaje de riqueza detentada por el $1 \%$ más rico de la población se ha doblado desde los años 70 (entonces se situaba en torno al 20\%), y ha vuelto a los niveles de los años 20 ( ¡antes de la implantación de la fiscalidad progresiva!). Semejante regresión en la distribución de la renta ha permitido afirmar a LESTER THUROW que «ningún país, sin experimentar una revolución o una derrota militar, ha experimentado nunca un incremento de la desigualdad tan rápido como el de las dos últimas décadas en Estados Unidos» (citado por Estefanía, J., Contra el pensamiento único, cit., p. 293). 
de pobres [casi 4 veces menos]) (44). Y la brecha entre ricos y pobres tiende a ampliarse: se ha calculado que los ingresos de los 40 millones de norteamericanos más pobres disminuyeron como promedioen un $10 \%$ durante la década de los 80 .

Todas estas realidades integran el «lado oscuro» de los EE.UU., habitualmente silenciado por el cine y la TV. Uninforme de la Oficina Presupuestaria del Congreso U.S.A. ha llegado a reconocer la existencia de una «guerra de clases» larvada en la sociedad norteamericana (45); una guerra de clases que se manifiesta, por ejemplo, en las increíbles tasas de criminalidad. EnEE.UU. tienen lugar anualmente entre 20.000 y 25.000 homicidios (lo cual supone una muerte violenta cada 2025 minutos; sólo en la ciudad de Nueva York se cometen 5 homicidios diarios); los EE.UU. ocupan el segundo lugar del mundo (después de Ruanda) en el porcentaje de población encarcelada: más de un millón de ciudadanos norteamericanos se encuentran actualmente en prisión, y más de tres millones están sometidos a control judicial (46).

Bien: el modelo alternativo de capitalismo al que se refiere ALBERT es el «modelo renano» (Alemania, Suiza, Austria, Suecia...). Llevaría demasiado tiempo exponer todas las diferencias entre ambos modelos. Retengamos solamente lo que atañe más directamente a nuestro tema: el sistema de protección social ocupa un lugar verdaderamente central en el capitalismo renano; los ciudadanos alemanes, por ejemplo, están muy ampliamente protegidos contra los principales riesgos sociales (enfermedad, accidente de trabajo, desempleo...) y gozan de un régimen básico de jubilación muy ventajoso. Las diferencias afectan, no sólo a la extensión y la intensidad de la protección social (mucho más amplias en el «modelo renano» que en el «neoamericano»), sino también a la concepción de la misma: mientras la mentalidad norteamericana tiende a ver la seguridad social como un lastre para el presupuesto, una limosna para fracasados que fomenta la pereza y la irresponsabilidad, la mentalidad «renana», en cambio, ve la seguridad social como una conquistairrenunciable de la civilización, una institución imprescindible para el consenso social y el desarrollo económico... La concepción de la empresa

(44) Albert, M., op. cit., p. 49; el número de trabajadores a tiempo completo que viven por debajo del umbral de pobreza aumentó en un 50\% en EE.UU. entre 1979 y 1994 (datos en TOINET, M.F., «Emplois flexibles, societé en miettes», cit., p. 59).

(45) Albert, M., op. cit., p. 49.

(46) Albert, M., op. cit., p. 44. 
es también muy diferente en uno y otro modelos: mientras en EE.UU. la empresa es vista exclusivamente como un negocio, una máquina de generar beneficios, en los países renanos la empresa es sentida como una verdadera comunidad de intereses y responsabilidades, basada en la lealtad recíproca (47). Ese affectio societatis, ese sentimiento de corresponsabilidad y de pertenencia a la empresa, se consigue a través de principios como la contratación a largo plazo (tendencialmente vitalicia), la remuneración de la antigüedad, la formación permanente de los trabajadores, el sistema rígido y jerárquico de ascensos (las carreras meteóricas son mucho más improbables en Alemania que en EE.UU., pero también lo son las «caídas sin red»...), las diferencias salariales moderadas (el abanico de retribuciones es mucho más compacto en Alemania que en EE.UU.), la participación de los trabajadores en la adopción de decisiones empresariales a través de diversos órganos de cogestión (Mitbestimmung)... Otros rasgos de los países del «modelo renano» (rasgos conectados entre sí por vínculos que aquí no tenemos tiempo de detallar) son: desigualdad social mucho más atenuada que en EE.UU., presión fiscal elevada, cuasi-inexistencia de la pobreza, reglamentaciones laborales exigentes, sistema de enseñanza pública muy sólidoen los niveles primarios y medios, existencia de sindicatos muy poderosos (pero extraordinariamente responsables), activa participación de los ciudadanos en la vida pública (frente al ultraindividualismo de los EE.UU.), partidos políticos poderosos y bien estructurados, altas tasas de participación electoral (oscilan en torno al 85\%-90\%; en EE.UU. la participación electoral suele situarse en torno al 50\%)...

Bien, la conclusión que se desprende de los análisis de ALBERT es que el «modelo renano» es a todas luces más justo, más racional y más eficaz que el «modelo neoamericano»: genera un tipo de sociedad más equilibrada, más civilizada, e incluso más productiva desde el punto de vista material (el libro de ALBERT contiene interesantes consideraciones sobre el Wirtschaftswunder alemán de los 50-60, una proeza económica que no se vio entorpecida-sino, antes al contrario- estimulada por el ambicioso sistema de protección social) (48). Y bien, la gran paradoja del mundo actual estriba en que, pese a su evidente superioridad, el «modelo renano» se encuentra a la defensiva en todas partes, mientras que el «modelo neoamericano» no cesa de ganar terreno. Por ejemplo,

(47) Albert, M., op. cit., p. 105 y ss.

(48) Albert, M., op. cit., p. 118 y ss. 
si se pregunta a un inmigrante del Tercer Mundo si prefiere establecerseenEE.UU. oen Alemania, es seguroque9 decada 10escogerán los EE.UU.; el mitode los EE.UU. como «tierradelasoportunidades» conservasu vigencia, pese a todos los desmentidos delarealidad.Los dirigentes de los países ex-comunistas han optadomayoritariamente por estrategias neoliberales a la hora de diseñarla transición al capitalismo: su modelo de referencia son los EE.UU., y noEuropa Occidental.El capitalismo americano, con todas sus deficiencias, le está ganandola batalla psicológica, publicitaria ideológica al capitalismo «renano», que es más justo y eficaz.

Las razones que podrían explicar esa sorprendente victoria del más débil son de varios tipos. De un lado, la conocida y aparentemente imparable hegemonía cultural norteamericana: los medios de comunicación, las tele-series, el cine, etc., difunden por todo el planeta una imagen seductora de los EE.UU.; elidiomainglés se ha convertido en un esperanto cuasi-ecuménico; el sistema de enseñanza superior norteamericano atrae a los mejores cerebros del mundo, y de esta forma ejerce una influencia universal: a través de esas élites internacionales formadas en sus universidades, EE.UU. consigue sembrar por todas partes sus valores y sus métodos, «que los antiguos estudiantes extranjeros de Stanford o Berckeley propagarán una vez de regreso en sus países de origen» (49).

Pero existe otra clave explicativa, de carácter psicológico, sobre la que ALBERT insiste de manera especial: el capitalismo americano es más espectacular, más efectista, más «hollywoodense» que el capitalismo renano. La economía social de mercado depara trayectorias vitales confortables, pero relativamente previsibles: no habrá ascensos ni enriquecimientos fulgurantes, pero tampoco catástrofes; el individuo se sabe protegido por la «red de seguridad» del Estado asistencial. El capitalismo renano es «virtuoso, igualitario, prudente, discreto» (50); todo él está teñido con el gris de la virtud, y resulta, en este sentido, poco excitante (la virtud siempre resulta aburrida...). El capitalismo americano, en cambio, posee el atractivo de las emociones fuertes, del «vivir peligrosamente»: promete recompensas muy rápidas y muy espléndidas a los vencedores, y amenaza con penalidades absolutamente reales a los perdedores. En los EE.UU. la competición socio-económica se desarrolla «sin red de seguridad»; el «vértigo» de los participantes es mayor, pero es sabido que el vértigo y el peligro poseen un

(49) Albert, M., op. cit., p. 40.

(50) Albert, M., op. cit., p. 184. 
atractivo morboso para muchas personas (es la emoción del jugador, del apostador...). La clave de la capacidad fascinadora del capitalismo U.S.A. está relacionada, pues, con el factor de la movilidad social (mayor que en Europa): sólo allí son posibles los enriquecimientos meteóricos (al estilo BILL GATES) y las caídas en desgracia igualmente imprevisibles y apabullantes (como la de MICHAEL MILKEN, el inventor de los junk bonds $\mathrm{o}$ «bonos basura», considerado en su momento un genio de las finanzas, y que actualmente se encuentra en la cárcel; no sería muy complicado encontrar equivalentes españoles: también nuestro capitalismo parece haberse convertido en los últimos tiempos en algo muy parecido al Crazy Horse Saloon o al casino de Las Vegas...).

\section{Conclusiones}

Bien, en todo caso, del análisis comparativo abordado por ALBERT se desprende una sólida refutación de las críticas ultraliberales al Estado social. Las cosas no son tan sencillas como ellos pretenden hacernos creer: no es cierto que el recorte del Estado asistencial, las privatizaciones indiscriminadas, la desreglamentación del mercado laboral, etc., garanticen infaliblemente una economía saneada y un alto índice de crecimiento. GERHARD BÄCKER, por ejemplo, muestra por medio de estadísticas cómo en Alemania los altos costes salariales y las gravosas cotizaciones sociales son ampliamente compensados por los incrementos de productividad conseguidos por una mano de obra motivada, bien formada y bien pagada (51). Adquiere así plausibilidad la tesis de DAVID HARRIS, según la cual las prestaciones sociales representan, no una rémora, sino un acicate para el sistema productivo; sólo así puede entenderse que los 30 años de máximo crecimiento económico en Europa (1945-1975) vengan a coincidir precisamente con la etapa de la construcción del Estado asistencial: «la existencia de Estado del Bienestar -afirma HARRIS- es parte de la explicación del éxito alcanzado por las economías europeas de posguerra», pues «la educación y la atención sanitaria gratuitas contribuyen a la productividad laboral» (52).

En la misma dirección apuntan los argumentos de GERHARD BÄCKER: la

(51) BÖCKER, G., «Sozialpolitik zwischen Abbau und Umbau», cit., p. 155.

(52) Harris, D., La justificación del Estado de bienestar, trad. de J.J. Fernández Cainzos, Instituto de Estudios Fiscales, Madrid, 1990, pp. 105-106. 
economía productiva y el sistema asistencial se necesitan recíprocamente. En este sentido, BÄCKER apunta que el debate sobre el Estado social se ve con frecuencia desvirtuado por el hecho de que, mientras los «costes» sociales son fácilmente cuantificables, los «rendimientos» del sistema asistencial (su utilidad, sus beneficios económicos y sociales) son, en cambio, mucho más difícilmente expresables en términos contables (aunque no por ello menos importantes). El Estado asistencial garantiza una mano de obra sana, formada, cualificada, capaz de adaptarse a las innovaciones tecnológicas: eso posee un valor económico inmenso, aunque sea imposible precisarlo en cifras. Sobre todo, elEstado asistencial contribuye en forma decisiva a la paz social; hemos visto que las sociedades del «modelorenano» son más igualitarias, más estables, más cohesionadas, más participativas, más basadas sobre el consenso: todas estas características, además de poseer valor por sí mismas, favorecen también decisivamenteeldesarrolloeconómico. Noes cierto, por tanto, que la eficacia económica deba necesariamente alimentarse de la injusticia social. La alternativa excluyente ante la que pretenden situarnos los ultraliberales (ocrecimiento económico, o justicia social) es una falsa alternativa (53).

En lo que se refiere a las predicciones apocalípticas que examinábamos al comienzo de la exposición (por ejemplo, la idea según la cual existe un límite objetivo para el crecimiento del gasto público, más allá del cual se desencadena la catástrofe), interesa recordar que ese tipo de previsiones agoreras existieron ya en el siglo XIX (LEON SAY, por ejemplo), y desde entonces son invocadas regularmente por diversos economistas y políticos. Lo que ocurre es que esa «barrera estructuralmente infranqueable» va siendo desplazada hacia arriba, sin que termine de producirse la esperada catástrofe. El mismo KEYNES escribió en 1926 una carta abierta al ministro de Finanzas francés, en la que expresaba su convicción de que el gasto público nunca podría sobrepasar el $25 \%$ del producto nacional (es sabido que hoy en algunos países se sitúa en torno al 45\%).

Algo parecido cabría decir sobre las predicciones catastrofistas sobre envejecimiento de la población, insostenibilidad de las pensiones, etc. Determinadas proyecciones demográfico-económicas son optimistas acerca de la sostenibilidad de las pensiones de jubilación en Europa, al menos hasta el 2040 (54). También

(53) BöcKer, G., «Sozialpolitik zwischen..»., cit., pp. 158-159.

(54) Así, la propuesta por el Prognos Institut, que combina la evolución previsible a lo largo de los próximos 50 años de variables tales comola estructura generacional de la población, el nivel 
W.J. BAUMOL, uno de los grandes economistas actuales, partiendo de la constatación elemental de que en las prestaciones sociales no puede darse el tipo de incremento de productividad que se da en la fabricación de bienes materiales (por ejemplo, quizás hoy es posible fabricar un automóvil en 20 veces menos tiempo que hace 50 años; pero, en cambio, el tiempo que necesita un maestro para enseñar a leer a un grupo de niños o el tiempo que necesita un médico para examinar a un paciente probablemente sea el mismo que hace 50 años: en la educación y en la atención sanitaria, el «incremento de la productividad» [si lo computamos en unidades de tiempo necesarias para conseguir ciertos resultados] es prácticamente imperceptible), demuestra que es inevitable que los costes relativos de servicios como la educación o la sanidad vayan incrementándose (y que, por tanto, la inversión en educación y sanidad represente un porcentaje cada vez mayor respecto al P.I.B.), pero eso no implica que haya de desembocarse en una situación insostenible, porque el incremento de la productividad global en otros sectores permite afrontar esos costes crecientes (y él lo demuestra con cifras) (55).

Tampocoes ineluctable el círculo vicioso en virtud del cual la rivalidad comercial internacional empuja a los países «civilizados» a percibir las medidas de protección social y laboral como una rémora y una desventaja comparativa (y, por tanto, a desprenderse progresivamente de ellas, con lo cual terminaría produciéndose una igualación «por abajo» en lo que se refiere a derechos sociales y condiciones laborales). Una solución (por la que, por cierto, la O.I.T. no deja de batallar) consistiría en la incorporación a los acuerdos comerciales bilaterales y multilaterales de «claúsulas sociales» que penalizasen a los países que no respetasen ciertas condiciones mínimas en cuanto a jornada laboral, condiciones de trabajo, derechos sindicales, niveles de salario, etc. La generalización y aplicación de esas «claúsulas sociales» (que, por señalar sólo un ejemplo, prohibirían las importación de productos en cuya fabricación hayan participado niños) permitiría que el comercio internacional y la mundialización económica, en lugar de ser fuerzas contrarias a los derechos humanos (como parecen ser hasta ahora), se convirtiesen en

de empleo, el progreso tecnológico, el incremento de la productividad, etc. (los cálculos se refieren sólo a Alemania); vid. «Prognos-Gutachten 1995: Perspektiven der gesetzlichen Rentenversicherung für Gesamtdeutschland vor dem Hintergrund veränderter politischer und ökonomischer Rahmenbedingungen», en Deutscher Rentenversicherungsträger Schriften, Bd.4, 1995.

(55) Baumol, W.J., «El bienestar, salvado por Mozart» en PIRANI, M., El futuro de la economía, cit., p. 50 y ss. 
factores favorecedores de la propagación de los derechos humanos (56).

Ahora bien, rechazar el fatalismo economicista ultraliberal no debe conducir a encastillarse en una actitud inmovilista. Sería lamentable responder al fundamentalismo liberal con otro fundamentalismo anti-mercado, de signo inverso (y de hecho circula ya cierto discurso anti-liberal facilón y demagógico, desde Julio Anguita al subcomandante Marcos...). En mi opinión, las críticas liberales deben ser escuchadas y tomadas en serio (por eso les dediqué un amplio espacio al comienzo de la exposición), para recoger lo que en ellas pueda haber de aprovechable y constructivo. No se trata de mantener a ultranza «todo tal como está»; esa actitud quietista sería precisamente la que más podría poner en peligro la supervivencia del Estado social. Las propuestas de renovación y actualización delEstado asistencial deben, en mi opinión, ser debatidas sin dogmas ni prejuicios, siempre que por «renovación» no se entienda (en el fondo) «desmantelamiento». Los partidarios del Estado social somos los más interesados en detectar y subsanar sus posibles rigideces, zonas necrosadas, anquilosamientos burocráticos, irracionalidades, hemorragias presupuestarias evitables, planteamientos anacrónicos, etc., precisamente para garantizar la supervivencia global del Estado del Bienestar (57). Esas estrategias modernizadoras incluirán, sin duda, la reconsideración del orden de prioridades en lo que se refiere a las necesidades sociales dignas de atención, la reestructuración interna del gasto social (lo cual no es lo mismoque su reducción, sino una redistribución interna entre las distintas partidas del presupuesto social).

Y entre las diversas propuestas modernizadoras (que no detallaré aquí, para no abusar aún más de vuestra amable atención), me parece que revisten un especial interés las que intentan potenciar y aprovechar los espacios sociales intermedios

(56) La idea de las «claúsulas sociales» es desarrollada de manera interesante en JULIEN, C., «Ces «élites» qui régnent sur des masses de chômeurs», cit., p. 10.

(57)Esa es la postura de G. BöCKER; BöCKER, G., «Sozialpolitik zwischen. .»., cit., pp. 158-159 y 162. En el mismo sentido se pronuncia L. De SEBASTIÁN: «[Para mantener elEstado asistencial] habrá que hacer un recorte quizá del nivel y el monto de las prestaciones; habrá que vigilar mejor para evitar abusos; habrá que aumentar la eficacia del sistema. Todo esto es bien diferente de desmontarloen su integridad» (Neoliberalismo global, cit., p. 104). Muy similar es la posición de J. ESTEFANÍA: «ElEstado del Bienestarnecesita una urgente actualización para aplicar los derechos a quienes verdaderamente los necesitan; locual significa una revisión de los niveles de providencia (en unos casos al alza, en otros a la baja) y de sus beneficiarios, eliminando los corporativismos [...] Ser conservador conduce al fracaso». (Contra el pensamiento único, cit., p. 99). 
al Estado y el mercado. PIERRE ROSANVALLON, por ejemplo, explica que es un error mantener el debate sobre el Estado asistencial dentro de la alternativa excluyente «o Estado, o mercado». Él insiste en la necesidad de descentralizar y socializar la función asistencial, esto es, de impulsar formas de solidaridad social que no impliquen necesariamente la estatalización y la burocratización (58). De esa forma, el Estado podría ser descargado de una parte de sus prestaciones y responsabilidades, que ya empiezan a desbordarle (me refiero al famoso fenómeno de «sobrecarga delEstado» [government overload], al que con frecuencia aluden los críticos liberales). Ahora bien, esa desestatalización de servicios y funciones no debe ser confundida con su privatización (en el sentido de «mercantilización»); los servicios en cuestión no son devueltos al mercado (pues ya sabemos que la lógica del mercado penaliza a los más débiles, etc.), sino que son transferidos a esos espacios sociales intermedios, esa «tierra de nadie» a medio camino entre el Estado y el mercado, en la que, por ejemplo, florecen fenómenos como el voluntariado y las O.N.G. Naturalmente, no se trataría de sustituir el Estado asistencial «en bloque» por asociaciones filantrópicas privadas (eso supondría un retorno al siglo XIX). Pero sí puede ser una línea de evolución interesante que el Estado, sin dejar de ofrecer a todos unas prestaciones mínimas y ocupar un lugar central en el sistema, delegue o descentralice una parte de sus funciones asistenciales a través de este tipo de entidades (59). También R.M. TITMUSS,

(58)RoSANVALLON considera que «si hay un futuro para elEstado delBienestar, será un futuro pluralista». Por pluralismo entiende desburocratización, descentralización, «autonomización», transferencia de servicios a entidades no público-estatales (pero tampoco mercantiles)... Insiste en la necesidad de potenciar un «tercer espacio», más allá delEstado y del mercado(RosANVALLON, P. , La crise de l'Etat-providence, cit., p. 112 y ss.). Esta reinvención del Estado asistencial en clave descentralizada-autogestionaria podría quizás conectar con las inquietudes de lallamada «izquierdalibertaria» (movimientos ecologistas, pacifistas, feministas, etc.), laizquierda post-materialista que, como indica EsTEFANÍA (op. cit., p. 124), discrepa del modelo keynesiano tradicional de «crecimiento+distribución». Las relaciones de esa «nuevaizquierda» (que se nutre de los que HABERMAs ha llamado «disidentes de la sociedad industrial») con la socialdemocracia welfarista-keynesiana tradicional han sido analizadas por W. Merkel en MERKEL, W. «Los desafíos de la socialdemocracia a finales del siglo XX», incluido en MERKEL, W.(ed.), Entre la modernidad y el postmaterialismo. La socialdemocracia europea a finales del siglo XX, trad. de J.C. Monedero, Alianza, Madrid, 1994, p. 16 y ss.

(59) También defiende posiciones similares Tом Воттомове; vid. Воттомове, T., Citizenship and Social Class: Forty Years On, Pluto Press, Londres, 1992, p. 82. 
que es un clásico de la teoría del Estado social y los derechos sociales, insistía [en la última edición de su obra «Social Policy»] en el protagonismo creciente que debería corresponderen el futuro a las organizaciones caritativas, las agrupaciones de consumidores y las asociaciones de ayuda mutua, debidamente estimuladas, subvencionadas y vigiladas por el Estado (60).

Ya para finalizar, me gustaría evocar unas interesantes afirmaciones de $\mathrm{P}$. RICOEUR acerca del temaque nos ocupa. RICOEUR considera que elEstado social representa un compromiso histórico basado sobre un delicado equilibrio entre la lógica técnico-económica y la lógica ético-política. Y, segúnél, el dilema al que se va a enfrentar Europa en los próximos años es si debe o no permitirse la destrucción de ese compromiso histórico en nombre del liberalismo económico (61).

Quizás deberíamos, por tanto, aspirar, no a una sociedad de mercado, sino a una sociedad con mercado, esto es, una sociedad que ponga la indiscutible eficacia productiva del mercado capitalista al servicio de la justicia, del bienestar social y del desarrollo de las personas. El mercado debería ser una herramienta al servicio de la sociedad, y no al revés; debemos evitar que la sociedad en su conjunto sea informada por el mercado, subyugada por el mercado (62).

Concluyo con esto mi exposición. No me queda sino reiterar mi gratitud a organizadores y oyentes, y esperar con interés vuestas intervenciones o preguntas.

(60) Titmuss, R.M., Social Policy, Unwin Hyman, Londres, 1988, p. 34 y ss.

(61) Ricoeur, P. , «Ethique et Politique», Esprit, Mayo 1985, p. 5 y ss.

(62) Evitar la sacralización del mercado como un fin en símismo; recordar que se trata de un medio al servicio de la sociedad: éste podría, quizás, ser el nuevo minimum ideológico en torno al cual nuclear la reconstrucción de la izquierda, aturdida todavía por las consecuencias del colapso comunista y encogida frente al triunfalismo neoliberal. Son interesantes, en este sentido, las consideraciones de F. OvEJEROLUCAS: «El mercado interesa, si interesa, porque interesan otras cosas. La igualdad es una de ellas. [...] a nadie le interesa como tal el mercado. Es un simple instrumento para organizar las tareas económicas, y, como cualquier otro instrumento, estará justificado si lo están los objetivos que permite alcanzar». (OveJERo, F., «El mercado, laigualdad y la izquierda», El País, 24-11-1997). En un sentido parecido se pronuncia un personaje tan interesante como G. SoRos (tiburón financiero «arrepentido» y reciclado en profeta postsocialdemócrata): «Podemos tener una economía de mercado, pero no debemos tener una sociedad de mercado. Los mercados reducen todo, incluidos los seres humanos (mano de obra) y la naturaleza, a mercancía. Además de los mercados, la sociedad necesita instituciones que sirvan a fines sociales comola libertad política y lajusticia social». (Soros, G., «Hacia una sociedad abierta global», El País, 23-12-1997). 